$2.36 \mathrm{mmol} / 1(1.6 \mathrm{mg} / 100 \mathrm{ml})$ if the 12 -hour steady-state serum lithium level was maintained at $1 \mathrm{mmol} / 1 .^{56}$ The mean dosage of Priadel required to maintain this level would be $1643 \mathrm{mg}$. Comparison of these results suggests that the peak serum lithium level would be certainly above $2 \mathrm{mmol} / \mathrm{l}$ (1.4 $\mathrm{mg} / 100 \mathrm{ml}$ ) and probably considerably above this in the patient described, as the patient was receiving a higher dosage of lithium. If the blood samples were taken just before administration of the whole dose of lithium, the peak serum lithium level would be even higher than this.

We still do not know how best to give lithium to maintain prophylaxis, but in view of the recent reports of renal damage following lithium toxicity ${ }^{7}{ }^{8}$ it is prudent to give lithium in such a way as to avoid levels in the toxic range. The majority of patients should receive lithium in at least a divided dose schedule.

S P TYRER

Queen's University,

Schou, M, et al, British fournal of Psychiatry, 1970 116, 615

${ }^{2}$ Cooper, T B, Bergner, P-E E, and Simpson, G M, American fournal of Psychiatry, 1973, 130, 601.

Amdisen, A, Danish Medical Bulletin, 1975, 22, 277. Bergner, P-E E, et al, British fournal of Pharmacology
$1973,49,328$.

Tyrer, $\mathrm{S} \mathrm{P}$, in Lithium in Medical Practice, eds $\mathrm{N}$ Johnson and $S$ Johnson, p 395. Lancaster, Medical and Technical Publishing, 1978.

Tyrer, S P, American fournal of Psychiatry, in press. Hansen, $\mathrm{H} \mathrm{E}$, et al, Proceedings of the European Dialysis and Transplant Association. London, Pitman Medical, 1977.

\section{Endometrial assessment}

SIR,-We have profound reservations abou the conclusions drawn by Dr J D Hutton and his colleagues (15 April, p 947). Endometrial cytology is notoriously difficult to assess, and whereas most experienced cytologists would be happy to differentiate between normal endometrial cells and the cells of adenocarcinoma this would not apply to the subtle changes described in cystic hyperplasia and adenomatous hyperplasia. The degree of experience required to grade these changes is considerable and could be provided only in a few centres. One can easily understand these problems, as pathologists may have difficulty in differentiating between the various hyperplasias, and they have much more tissue to examine.

The endometrial cell sampler may have a limited place as a screening procedure in postmenopausal women before they are given oestrogen therapy. In this group of patients satisfactory endometrium for histological examination is obtained in only about $12 \%$ of cases, whether the endometrium is obtained by dilatation and curettage ${ }^{1}$ or by Vabra aspiration. ${ }^{2}$

They also comment that the endometrial cell sampler is almost painless in comparison with the Vabra. Although accepting that the Vabra may be a little more painful, it is probably not significantly so. In a series of 348 Vabra aspirations performed at either Dulwich Hospital or the Birmingham and Midland Hospital for Women, $46(13 \%)$ were painless, $267(77 \%)$ had minimal or moderate pain, and only $35(10 \%)$ had severe pain. Although not strictly comparable, these results differ very little from Dr Hutton's series.

We would therefore urge caution before the endometrial cell sampler is used in the monitoring of postmenopausal patients on oestrogen therapy.

M E L PATERSON D W STURDEE

Department of Obstetrics and

Gynaecology,

Birmingham and Midland Hospital

for Women,

Birmingham

MARGARET THOM

J W W STUDD

King's College Hospital,

London SE5

1 McBride, J M, fournal of Obstetrics and Gynaecology of the British Commonwealth, 1954, 61, 691. Sturdee, D W, et al, British Medical fournal, in press.

\section{Demeclocycline in congestive cardiac} failure

SIR,-Dr D Zegers de Beyl and colleagues (25 March, p 760) demonstrated increased urine volume and sodium excretion with the use of demeclocycline in congestive cardiac failure intractable to conventional diuretics. Their explanation for this diuresis, based on experimental studies, suggests inhibition of antidiuretic hormone activity. Their data show a fall in urine osmolality commensurate with increasing urine volume, but urine osmolality remained hypertonic so that free water excretion was not apparently increased.

In congestive cardiac failure natriuresis from demeclocycline may be striking, even when urinary diluting capacity is inhibited by simultaneous "loop" diuretic administration, suggesting that natriuresis may be independent of free water excretion (see figure). Frusemide probably acts by blocking active chloride reabsorption in the thick ascending limb of the loop of Henle, ${ }^{2}$ simultaneously preventing free water formation and passive sodium reabsorption at their site. Metolazone blocks active sodium transport in the distal tubule. With combined use of frusemide and metolazone in the case shown in the figure, urine volume was maintained between 2 and 3 litres per day, presumably by inhibiting sodium reabsorption in the loop of Henle and the

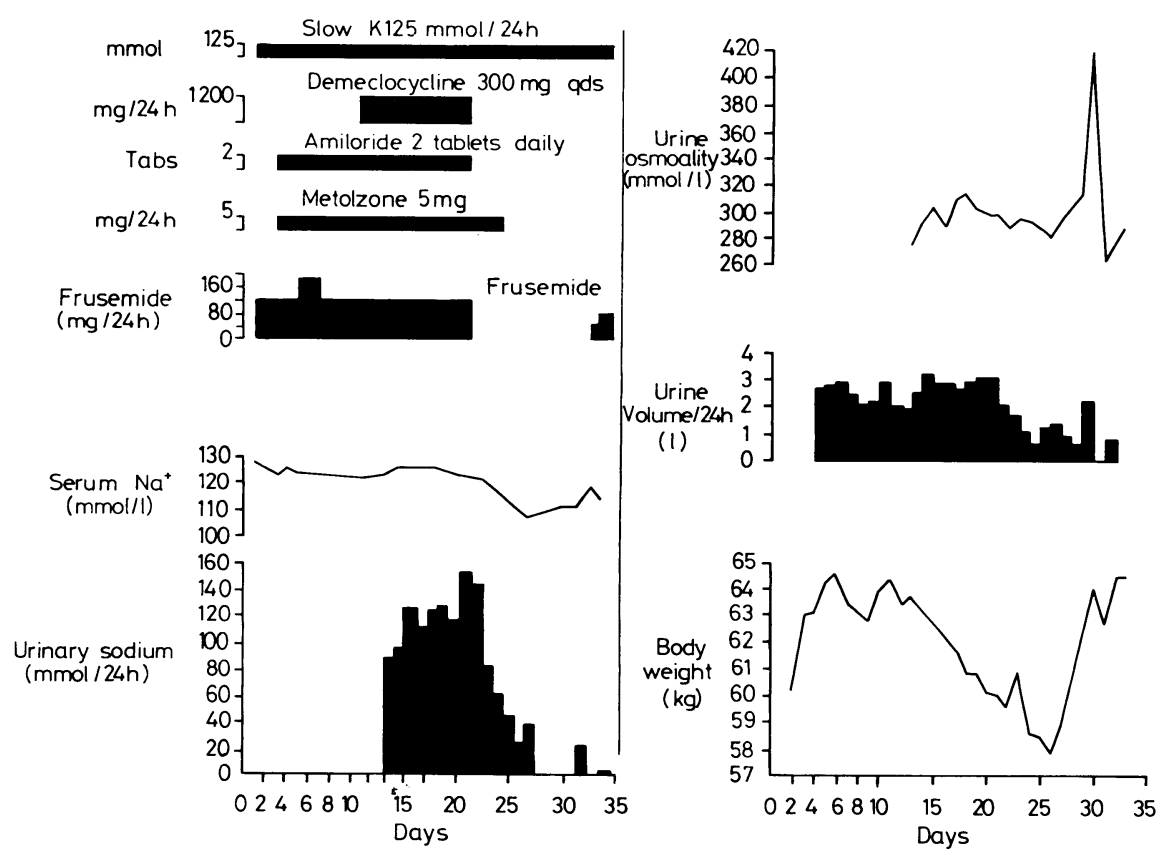

Conversion: SI to traditional units-Sodium: $1 \mathrm{mmol}=1 \mathrm{mEq}$. Osmolality: $1 \mathrm{mmol}=1 \mathrm{mosmol}$. distal tubule respectively. The addition of demeclocycline to these diuretics produced a sustained rise in urine volume, and a considerable natriuresis with associated fall in body weight. A proximal site of action for demeclocycline may be speculated on.

The $1200 \mathrm{mg}$ starting dose of demeclocycline used by Dr Zegers de Beyl may be excessive, as in our patient, a 60-year-old man with congestive heart failure, resistant oedema, and hyponatraemia. Sodium depletion resulted and was accompanied by a further fall in serum sodium concentration. Urine osmolality rose slightly during natriuresis, indicating that this was predominantly a solute diuresis. We now employ a starting dose of $150 \mathrm{mg}$ of demeclocycline per day, when conventional diuretics are simultaneously given, and increase the dose by $150 \mathrm{mg}$ every fifth day. This regimen has proved a satisfactory adjunct to diuretic therapy in intractable congestive heart failure.

R R GHOSE $\mathrm{R}$ BONSER

Singleton Hospital

Swansea ${ }^{1}$ Burg, M B, and Green, W, American fournal of

\section{Aortography in infantile coarctation}

SIR,-Adequate demonstration of the hypoplastic segment of aortic arch in infants with preductile coarctation and intraventricular septal defect frequently requires arteriotomy, with its inherent risk to subsequent growth of that limb and other complications.

The use of a balloon angiocatheter floated anterogradely from the pulmonary artery through the patent ductus arteriosus into the aorta permits the affected segment to be easily demonstrated. After inflating the balloon with carbon dioxide or dilute contrast medium so as to completely occlude the descending aorta contrast is immediately injected into the aorta proximal to the balloon and retrograde filling of the aortic arch permits angiograms of high quality to be obtained. No adverse effect has 